\title{
Clinical Applications of Additive Manufacturing Models in Neurosurgery: a Systematic Review
}

\section{Aplicações clínicas de modelos de manufatura aditiva na neurocirurgia: uma revisão sistemática}

\author{
André Giacomelli Leal ${ }^{1,2(0)}$ Ricardo Ramina ${ }^{30}$ Paulo Henrique Pires de Aguiar ${ }^{4,5,6(1)}$ \\ Beatriz Luci Fernandes ${ }^{1}$ Mauren Abreu de Souza ${ }^{10}$ Percy Nohama1일
}

${ }^{1}$ Graduate Program on Health Technology, Pontifícia Universidade Católica do Paraná, Curitiba, Paraná, Brazil

Address for correspondence André Giacomelli Leal, PhD, Graduate Program on Health Technology, Pontifícia Universidade Católica do

2 Department of Neurovascular, Instituto de Neurologia de Curitiba, Paraná - PUCPR, Department of Neurovascular, Neurological Institute of Curitiba (INC), Curitiba, Paraná, Brazil

Curitiba, PR, Brazil

${ }^{3}$ Department of Neurosurgery, Instituto de Neurologia de Curitiba, (e-mail: andregiacomelli@inc-neuro.com.br).

Curitiba, Paraná, Brazil

${ }^{4}$ Department of Neurology, Medical School, Pontifícia Universidade Católica, Sorocaba, SP, Brazil

${ }^{5}$ Division of Neurosurgery at Hospital Santa Paula/Dasa, São Paulo, SP, Brazil

${ }^{6}$ Department of Research and Innovation Laboratory of Cellular and Molecular Biology, Faculdade de Medicina do ABC, Santo André, SP, Brazil

Arq Bras Neurocir 2021;40(4):e349-e360.

\begin{abstract}
Keywords

- 3D printing

- biomodel

- neurosurgery

Introduction Three-dimensional (3D) printing technologies provide a practical and anatomical way to reproduce precise tailored-made models of the patients and of the diseases. Those models can allow surgical planning, besides training and surgical simulation in the treatment of neurosurgical diseases.

Objective The aim of the present article is to review the scenario of the development of different types of available 3D printing technologies, the processes involved in the creation of biomodels, and the application of those advances in the neurosurgical field. Methods We searched for papers that addressed the clinical application of 3D printing in neurosurgery on the PubMed, Ebsco, Web of Science, Scopus, and Science Direct databases. All papers related to the use of any additive manufacturing technique were included in the present study.

Results Studies involving 3D printing in neurosurgery are concentrated on three main areas: (1) creation of anatomical tailored-made models for planning and training; (2) development of devices and materials for the treatment of neurosurgical diseases, and (3) biological implants for tissues engineering. Biomodels are extremely useful in several branches of neurosurgery, and their use in spinal, cerebrovascular, endovascular, neuro-oncological, neuropediatric, and functional surgeries can be highlighted.
\end{abstract}

received

July 22, 2021

accepted

August 13, 2021
DOI https://doi.org/ 10.1055/s-0041-1740646. ISSN $0103-5355$ (c) 2021. Sociedade Brasileira de Neurocirurgia. All rights reserved.

This is an open access article published by Thieme under the terms of the Creative Commons Attribution-NonDerivative-NonCommercial-License, permitting copying and reproduction so long as the original work is given appropriate credit. Contents may not be used for commercial purposes, or adapted, remixed, transformed or built upon. (https://creativecommons.org/ licenses/by-nc-nd/4.0/)

Thieme Revinter Publicações Ltda., Rua do Matoso 170, Rio de Janeiro, RJ, CEP 20270-135, Brazil 


\section{Resumo}

Palavras-chave

- impressão tridimensional

- biomodelos

- neurocirurgia
Conclusions Three-dimensional printing technologies are an exclusive way for direct replication of specific pathologies of the patient. It can identify the anatomical variation and provide a way for rapid construction of training models, allowing the medical resident and the experienced neurosurgeon to practice the surgical steps before the operation.

Introdução as tecnologias de impressão 3D proporcionam uma forma prática e anatômica de reproduzir modelos precisos e feitos sob medida dos pacientes e das doenças. Estes modelos podem permitir o planejamento cirúrgico, além de treinamento e simulação cirúrgica no tratamento de doenças neurocirúrgicas.

Objetivo o objetivo do presente artigo é revisar o cenário de desenvolvimento de diferentes tipos de tecnologias de impressão 3D disponíveis, os processos envolvidos na criação de biomodelos e a aplicação destes avanços no campo neurocirúrgico.

Métodos Procuramos por estudos que abordaram a aplicação clínica da impressão 3D em neurocirurgia nas bases de dados PubMed, Ebsco, Web of Science, Scopus e Science Direct. Todos os artigos relacionados ao uso de qualquer técnica de fabricação aditiva foram incluídos no presente estudo.

Resultados Estudos envolvendo impressão 3D em neurocirurgia estão concentrados em três áreas principais: (1) criação de modelos anatômicos adaptados para planejamento e treinamento; (2) desenvolvimento de dispositivos e materiais para o tratamento de doenças neurocirúrgicas, e (3) implantes biológicos para a engenharia de tecidos. Em vários ramos da neurocirurgia, os biomodelos são extremamente úteis. Pode-se destacar o uso em cirurgias de coluna, cerebrovasculares, endovasculares, neuro-oncológicas, neuropediátricas e funcionais.

Conclusões As tecnologias de impressão 3D são uma forma exclusiva de replicação direta das patologias específicas do paciente. Elas podem identificar a variação anatômica e fornecer uma maneira para a construção rápida de modelos do treinamento, permitindo que o residente médico e o neurocirurgião experiente pratiquem as etapas cirúrgicas antes da operação.

\section{Introduction}

The continuous advances in computer sciences brought several perspectives to the field of medicine. The possibility of visualization of internal organs using ultrasound (US) and computed tomography (CT) was followed by a significant progress with a better definition of the images through magnetic resonance imaging (MRI), and the medical horizons became wider. More recently, the virtual database could be changed in format, and the two-dimensional (2D) data became three-dimensional (3D) images. Ever since, with the improvement of the hardware and software myriad, the 3D virtual medical image became more convenient, easier to use, and with better resolution and interaction with the user. ${ }^{1,2}$

The technological advances have been driven by the needs of the industry and have been put forward by the advent of additive manufacturing (AM) techniques. This, in the field of the medicine, allows the production of 3D models of human structures, named as biomodels, beginning with data acquired from imaging exams. ${ }^{1,3}$

Currently, AM has been used by physicians to improve the precision of the diagnosis and of surgical planning and as a teaching tool for medical students and residents. It is particularly useful the surgeons, since 2D images cannot be easily understood in relation to the anatomical structures and complex anatomical irregularities. ${ }^{4}$

The available imaging exams can ensure a good visualization of the morphology of the organs to the surgeons; however, on some occasions, they are not effective for an appropriate surgical planning. Although digital graphs have become very similar to reality, the simulation of a surgical procedure remains difficult and is far from being applied, even when advanced technologies are adopted. Virtual reality simulators were developed for neurological surgery in an attempt to solve this problem. However, they are based on an extensive use of graphs with limited tactile feedback. Despite supplying 3D virtual images, the interpretation of these images depends on the rationale of the surgeon, who needs to transform the 2D images into 3D virtual images. On the other hand, real models of cerebral structures can provide a fertile tactile expression with no need of any visuospatial capacity of the surgeon to process the 2D images, since a touchable and real 3D model is available. ${ }^{5}$ 
In the surgical field, AM application reaches specialties such as bucomaxillofacial surgery, otolaryngology (ORL), orthopedics, cardiac surgery, and neurosurgery.

Bucomaxillofacial surgery applies 3D models for surgery planning in orthognathic patients, since the anatomy and the procedures in this area are quite complex. Three-dimensional printing technologies provide better functional and esthetic results, and increased satisfaction of patients due to a precise surgical planning. ${ }^{6-9}$

In the ORL field, the procedures can represent significant challenges, even for the most experienced surgeons, during resection of infiltrative tumor diseases and for the reconstruction of anatomical structures, mainly in the endoscopic approach and for skull base diseases. The use of AM allows the production of specific models from the patient, providing better surgical planning and preoperative simulation. ${ }^{10}$

In orthopedics, this technology affected mainly the surgical planning, being applied to spine, hip, pelvis, and shoulder lesions. Tailor-made prostheses are able to be adapted to the anatomy of each individual. ${ }^{11}$

Cardiovascular diseases also obtain benefits, since the biomodels can play an important role in the diagnosis and treatment. The technology is particularly useful to surgical and endovascular interventions, such as arterial endoprosthesis implantation. Likewise, in the literature, many reports described the use of biomodels in the treatment of valvar diseases. ${ }^{12-14}$

In neurosurgery, AM has numerous applications, which will be presented in detail.

\section{Methods}

We searched for papers that addressed the clinical application of 3D printing in neurosurgery. All articles related to the use of any AM technique were included in the present study. The exclusion criteria were: studies with no surgical or clinical relevance, not relevant to 3D printing, editorial comments, and image submissions. Articles were searched using the PubMed, Ebsco, Web of Science, Scopus, and Science Direct databases on December 30, 2018. Both Mesh terms and key terms were used to capture any publications not yet indexed. As keywords for the search, the following terms were used: Printing, Three-Dimensional [Mesh], 3D Printing, Three-Dimensional Printing, and Neurosurgery. There were no limits for the time of publication. A total of 159 articles were retrieved, from which 68 were excluded. Finally, 91 articles were selected for review (-Fluxogram $\mathbf{1}$ ).

\section{Results and Discussion}

\section{Additive Manufacturing: Concept}

Since its beginning, in the 1980s, AM was revolutionary in the development of objects. The term AM, formerly called rapid prototyping, is popularly known as 3D printing. It designates a gathering of technologies for manufacturing physical objects directly from a database that was generated by computer-aided design (CAD). These methods are quite

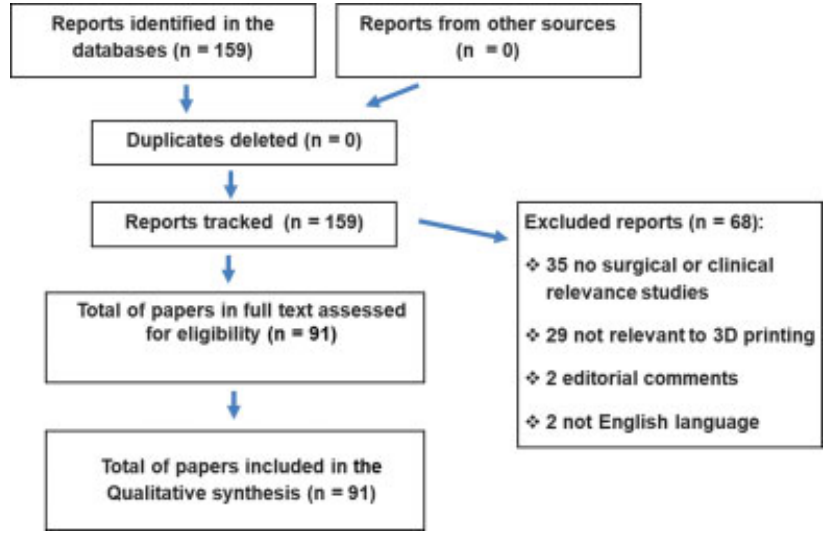

Fluxogram 1

peculiar, since the materials can be joined or bound, layer by layer, aiming to constitute the projected object. ${ }^{3}$

The term "rapid" associated to those processes is relative, since the construction of some prototypes can take from 2 to 72 hours, depending on the size and complexity of the object. ${ }^{15-17}$

A specific software that consists of the interface between the 3D model (CAD) and the AM machine decomposes the CAD model into several thin layers, which are piled one by one. The process of AM combines layers of material with the purpose of creating a solid object. The creation of objects with complicated internal characteristics is performed by the additive nature of this process, which cannot be achieved through other processes such as, for instance, machining, milling, and drilling, which are subtractive processes. ${ }^{18,19}$

Three-dimensional printing consists of a process to build 3D objects starting from a digital file. In this process, a 3D digital object is created using the design software (CAD). These virtual 3D objects are saved in a file whose format is recognized by the 3D printer (usually, in the STL format). ${ }^{20}$

All existing AM processes, until now, consist of five basic stages (- Figs. 1, 2 and 3):

1. Creation of a CAD model of the object that is being projected;

2. Conversion of the CAD file into an STL file;

3. Decomposition of the STL file into thin transversal layers;

4. Physical construction of the model, piling up one layer on another;

5. Cleaning and finishing of the model.

In this technology, several different processes of production are involved. Depending on the 3D printing process, the production of the model can be classified into 7 categories, according to the ISO/ASTM 52900 standard (2015) 19,21-23:

1. Binder jetting: when a liquid bonding agent is selectively deposited to join powder materials;

2. Directed energy deposition: a process in which focused thermal energy is used to fuse materials by melting as they are being deposited;

3. Material extrusion: when a material is selectively dispensed through a nozzle or orifice; 


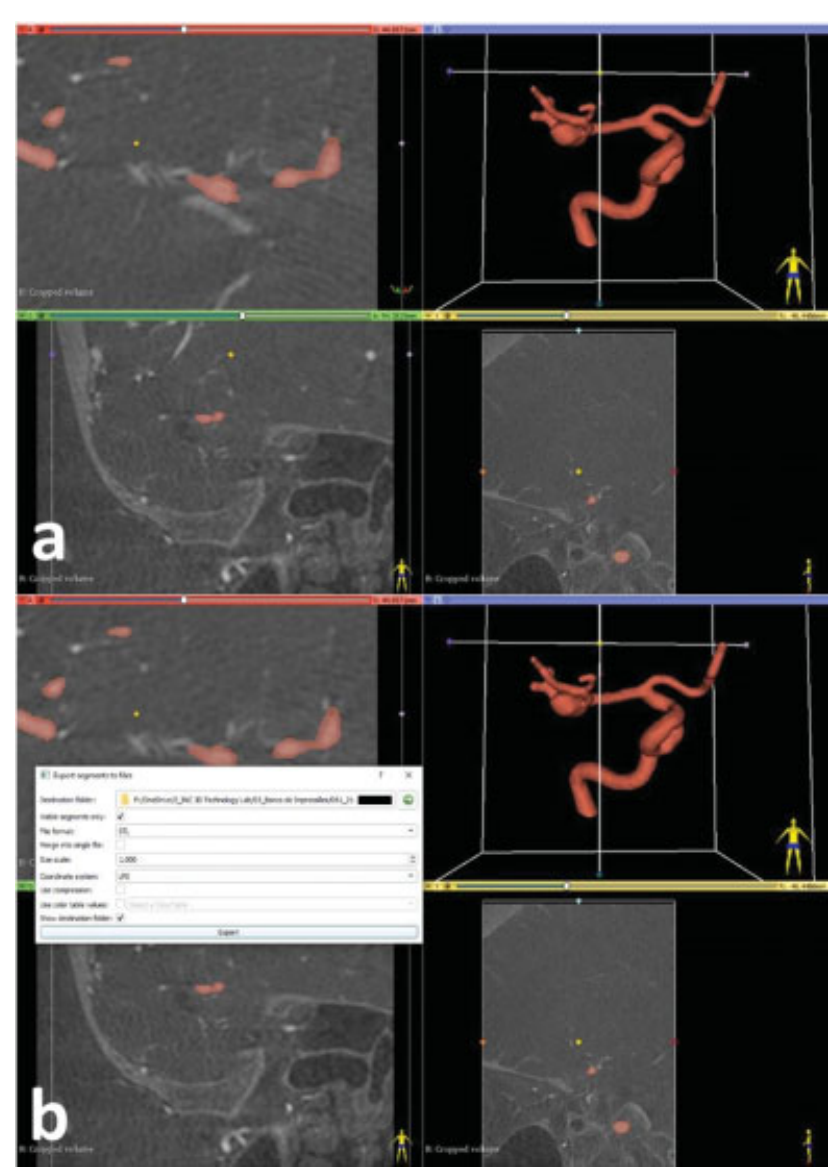

Fig. 1 (a) Creation of a CAD model of the object that is being projected; (b). Conversion of the CAD file into .STL extension.

4. Material jetting: a process in which droplets of build material are selectively deposited;

5. Powder bed fusion: when thermal energy selectively fuses regions of a powder bed;

6. Sheet lamination: a process in which sheets of material are bonded to form a part;

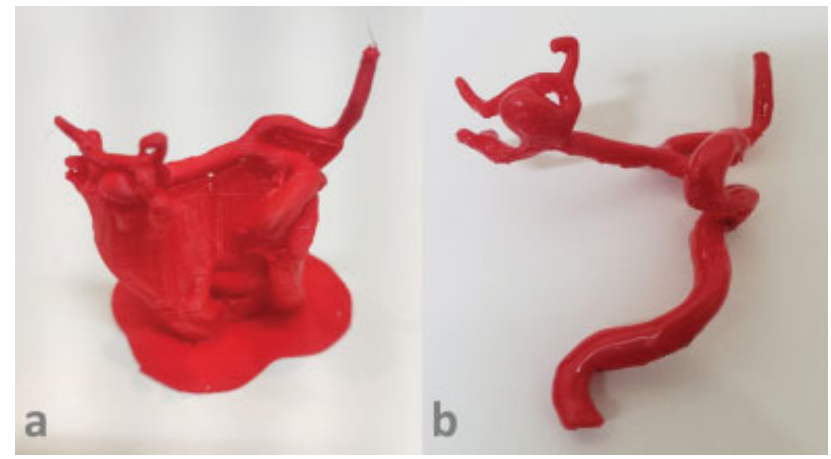

Fig. 3 ( $a$ and b) Cleaning and finishing of the model.

7. Vat photopolymerization: when a liquid photopolymer in a vat is selectively cured by light-activated polymerization.

\section{Additive Manufacturing in Neurosurgery}

Surgical procedures in neurosurgery can represent substantial challenges even for the most experienced surgeons, mainly in vascular and skull base surgeries. These challenges rise when handling lesions located inside or near the critical structures of the brain, or anatomically complex lesions.

Since its introduction in neurosurgery in $1999,{ }^{24}$ 3D printing has demonstrated its ability to aid in neurosurgical procedures. The comprehension of the brain structures is enhanced with the use of 3D biomodels before surgery. Moreover, 3D printing configures a promising opportunity for the preoperative training of the neurosurgeon. It is known that the excessive manipulation of intracranial nerves or vessels during the resection of a brain tumor, for instance, delays the surgery and constitutes a factor that can lead to neurological deficits, which, sometimes, are irreversible. ${ }^{25}$

Today, in surgical practice, the availability of an imageguided surgery configures a component in the development of surgical skills. ${ }^{26}$ The virtual reality (VR) systems for surgical simulation demonstrate promising results. ${ }^{27}$

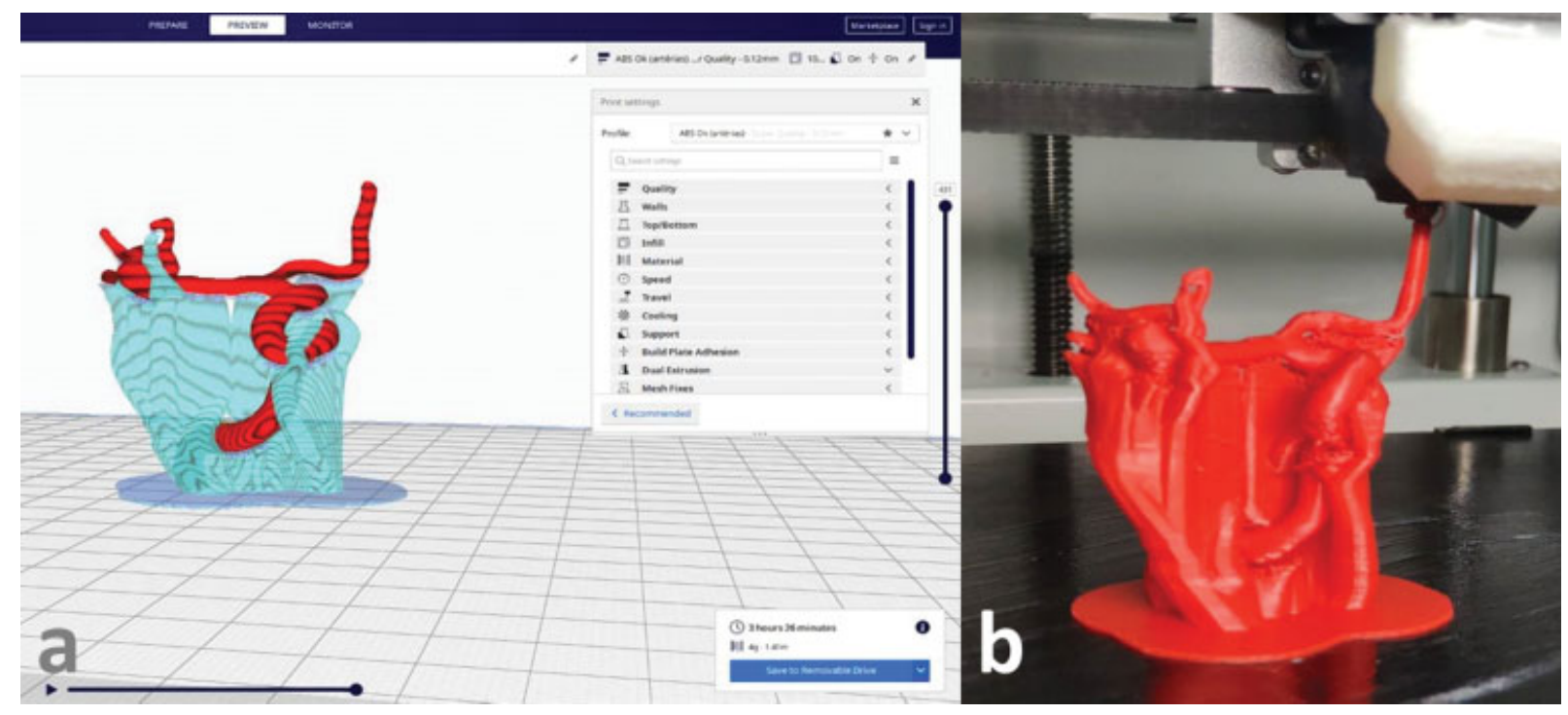

Fig. 2 (a) Decomposition of the STL file into thin transversal layers. (b) Physical construction of the model, piling up one layer on another. 
However, these systems are usually expensive, and supply only limited tactile feedback. In Brazil, the use of cadaver specimens it is still very restricted, since it depends on the availability of resources and biohazard issues. Studies in animals raise ethical questions and cannot always provide a realistic representation of the human anatomy. ${ }^{10}$

The projecting and manufacturing of anatomical biomodels are motivated by the need for realistic and reproductible models for surgical planning, training, and simulation. The development of 3D models has the potential to provide a series of advantages for neurosurgery, such as an educational perspective to both physicians and patients, and even to enable a surgical simulation.

Studies involving 3D printing in neurosurgery are concentrated on three main areas: (1) creation of anatomical tailor-made models for planning and training; (2) development of devices and materials for the treatment of neurosurgical diseases; and (3) biological implants for tissues engineering. ${ }^{28}$

Biomodels are extremely useful in several branches of neurosurgery. We can highlight the use in spinal, cerebrovascular, endovascular, neuro-oncological, neuropediatric, and functional surgeries.

Ideal guidelines for the acquisition of $\mathrm{CT}$ images were evaluated and determined that the acquired images should have a thickness of $2 \mathrm{~mm}$, and this data was adapted for the creation of 3D models. $^{29,30}$

However, with the advances in CT and 3D printer technologies, the acquired images have thinner slices $(0.6 \mathrm{~mm})$, as presented elsewhere by one of the authors (Leal A. G.) of the present article, ${ }^{17}$ and can generate models with more details and precision.

Also, MRI was evaluated for 3D data acquisition, but the resulting models were of lower quality when compared with the biomodels derived from CT. However, when the brain is prototyped, MRI images are more suitable due to the low definition of CT for soft tissues. ${ }^{31}$

Biomodels of intracranial aneurysms (IAs) have been studied for preoperative planning and surgical training. ${ }^{32-34}$ Some published studies reported that the biomodels were anatomically precise when compared with the real anatomy of the patient acquired through images of cerebral angiographies. ${ }^{35-37}$ Among these studies, one of the authors of the present study (Leal A. G.) can be cited (-Fig. 4). ${ }^{17}$

It is known that one of the main difficulties during the microsurgical treatment of IAs consists in the appropriate choice of the clip to be used, due to anatomical variabilities and to the peculiarities of each aneurysm. It is also common knowledge that IAs present wide and/or complex necks and that surgical planning is essential ${ }^{38}$ to avoid excessive manipulation of the intracranial vessels and an extended surgical time, which are factors that can predispose to intraoperative aneurismatic rupture ${ }^{39}$ Therefore, preoperative planning in touchable models that reproduce the surgical anatomy is enormously useful ( $\mathbf{- F i g u r e ~} \mathbf{5}$ ).

Although published studies ${ }^{40-42}$ have already demonstrated the usefulness of biomodels in the preoperative election of the surgical clip, studies with an objective evalu-

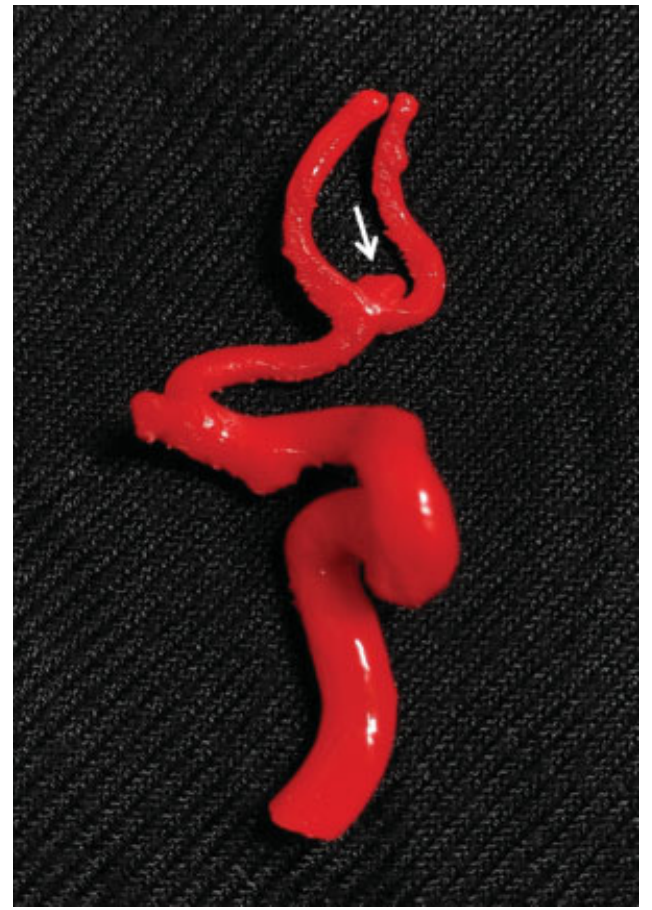

Fig. 4 Anterior communicating artery aneurysm (arrow) model.

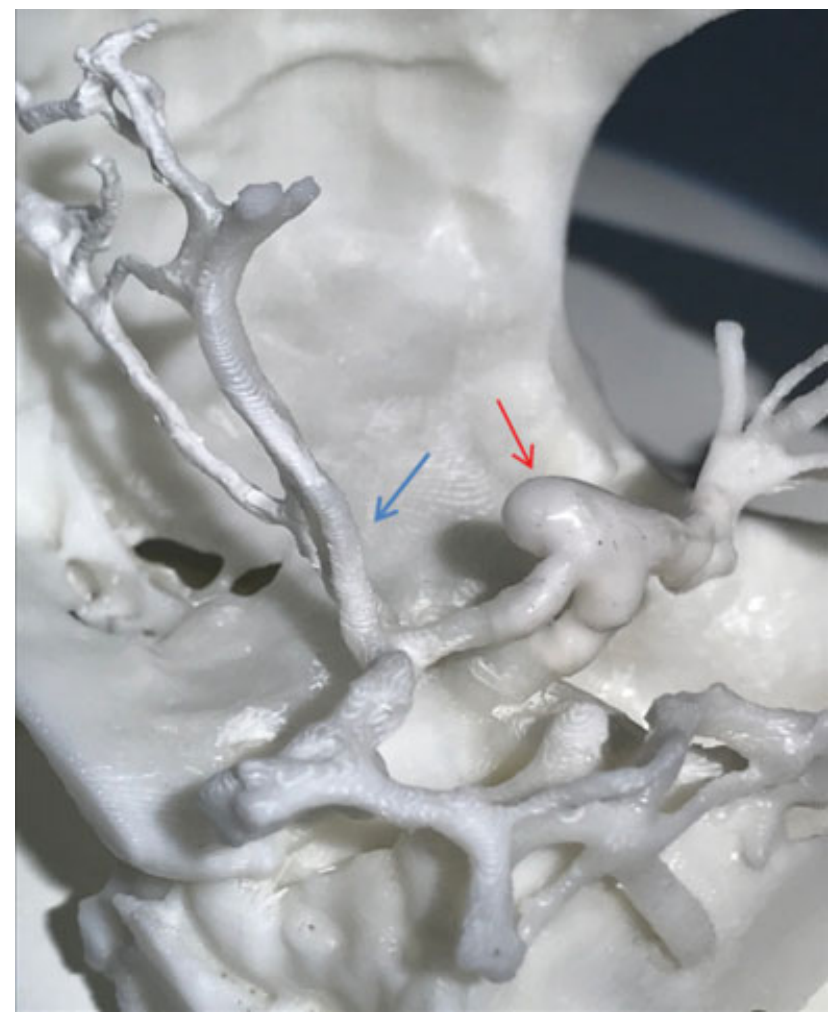

Fig. 5 Aneurysm model for preoperative election of the surgical clip. Flexible (red arrow) and hard (blue arrow) portions.

ation of the effectiveness of 3D modelling for surgical planning and training are still lacking. This project was recently published by the authors of the present study (-Fig. 6). - Table 1 lists the experience of the main author of the present study (Leal A. G.) in the use of IAs models. ${ }^{43}$ 
354 Clinical Applications of 3D Models in Neurosurgery Leal et al.

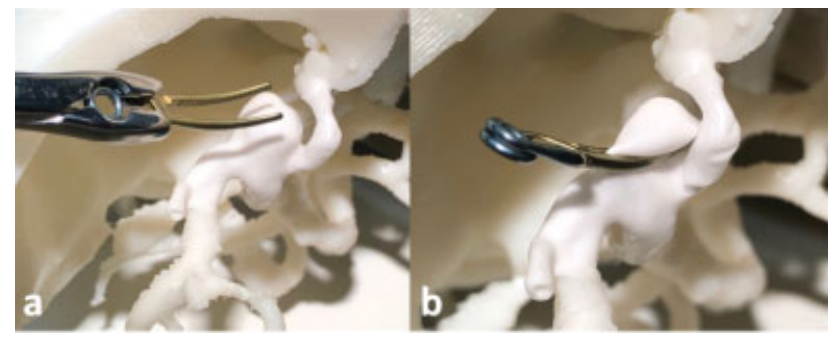

Fig. 6 Aneurysm model before (a) and after clip application (b).
Regarding cerebrovascular diseases, a study with 3D biomodels and arteriovenous malformations (AVMs) demonstrated that the intraoperative time was reduced, confirming that the printed models contributed to the surgical planning. ${ }^{44}$ Additive manufacturing technology is used to manufacture 3D models of the AVM and to facilitate the preoperative conversation with the patient and to serve as medical education for young surgeons. ${ }^{45,46}$

Carotid endarterectomy (CE) has also entered the AM era. Before the advent of AM, CE depended on the patients'

Table 1 Experience of the main author in the use of intracranial aneurysms models ${ }^{43}$

\begin{tabular}{|c|c|c|c|c|}
\hline Case & $\begin{array}{l}\text { Age } \\
\text { (years old) }\end{array}$ & Gender & IA location & IA size $\left({ }^{*}\right)$ \\
\hline 1 & 38 & $\mathrm{M}$ & R ICA (Bifurcation) & $7.3 \times 5.1 \mathrm{~mm}$ \\
\hline 2 & 65 & $\mathrm{~F}$ & L MCA (Bifurcation) & $3.6 \times 3.9 \mathrm{~mm}$ \\
\hline 3 & 71 & $\mathrm{M}$ & $\mathrm{ACOA}$ & $4.3 \times 3.4 \mathrm{~mm}$ \\
\hline 4 & 73 & $\mathrm{~F}$ & R ICA (Bifurcation) & $3.3 \times 4.5 \mathrm{~mm}$ \\
\hline 5 & 70 & $\mathrm{~F}$ & L ICA (Bifurcation) & $5.9 \times 5.6 \mathrm{~mm}$ \\
\hline 6 & 69 & $\mathrm{~F}$ & R ICA (Bifurcation) & $7.6 \times 3.9 \mathrm{~mm}$ \\
\hline 7 & 64 & $M$ & R ICA (Segment C7) & $2.6 \times 3.1 \mathrm{~mm}$ \\
\hline 8 & 63 & $\mathrm{~F}$ & L ICA (Bifurcation) & $3.8 \times 2.4 \mathrm{~mm}$ \\
\hline 9 & 55 & $\mathrm{~F}$ & R ICA (Bifurcation) & $4.8 \times 2.5 \mathrm{~mm}$ \\
\hline 10 & 67 & $\mathrm{~F}$ & R ICA (Segment C7) & $1.3 \times 2.0 \mathrm{~mm}$ \\
\hline 11 & 43 & $\mathrm{~F}$ & L ICA (Segment C4) & $4.5 \times 6.0 \mathrm{~mm}$ \\
\hline 12 & 66 & $\mathrm{~F}$ & L MCA (Bifurcation) & $5.1 \times 4.5 \mathrm{~mm}$ \\
\hline 13 & 54 & $\mathrm{~F}$ & MCA (Bifurcation) & $4.9 \times 4.4 \mathrm{~mm}$ \\
\hline 14 & 56 & $\mathrm{~F}$ & $\mathrm{ACoA}$ & $4.1 \times 2.1 \mathrm{~mm}$ \\
\hline 15 & 55 & $\mathrm{M}$ & L MCA (Bifurcation) & $2.4 \times 2.8 \mathrm{~mm}$ \\
\hline 16 & 69 & $\mathrm{~F}$ & L ICA (Segment C7) & $2.8 \times 7.6 \mathrm{~mm}$ \\
\hline 17 & 71 & $\mathrm{M}$ & $\mathrm{ACoA}$ & $4.6 \times 6.8 \mathrm{~mm}$ \\
\hline 18 & 50 & $\mathrm{~F}$ & R AChA & $2.7 \times 3.2 \mathrm{~mm}$ \\
\hline 19 & 63 & $\mathrm{M}$ & L MCA (Bifurcation) & $4.4 \times 5.9 \mathrm{~mm}$ \\
\hline 20 & 74 & $\mathrm{~F}$ & ACoA & $3.4 \times 4.6 \mathrm{~mm}$ \\
\hline 21 & 66 & $\mathrm{~F}$ & R ICA (Segment C4) & $7.4 \times 15.7 \mathrm{~mm}$ \\
\hline 22 & 66 & $\mathrm{~F}$ & L ICA (Segment C4) & $3.8 \times 5.2 \mathrm{~mm}$ \\
\hline 23 & 39 & $\mathrm{~F}$ & R MCA (Bifurcation) & $4.0 \times 1.8 \mathrm{~mm}$ \\
\hline 24 & 66 & $\mathrm{~F}$ & L ICA (Bifurcation) & $4.1 \times 4.0 \mathrm{~mm}$ \\
\hline 25 & 66 & $\mathrm{~F}$ & ACoA & $4.1 \times 2.8 \mathrm{~mm}$ \\
\hline 26 & 74 & $\mathrm{~F}$ & $\mathrm{ACOA}$ & $4.3 \times 3.7 \mathrm{~mm}$ \\
\hline 27 & 62 & $\mathrm{~F}$ & R ICA (Segment C6) & $3.5 \times 6.3 \mathrm{~mm}$ \\
\hline 28 & 51 & $\mathrm{~F}$ & R MCA (Bifurcation) & $3.0 \times 3.1 \mathrm{~mm}$ \\
\hline 29 & 57 & $\mathrm{~F}$ & R MCA (Bifurcation) & $6.3 \times 7.7 \mathrm{~mm}$ \\
\hline
\end{tabular}

Abbreviations: AchA, anterior choroidal artery; ACoA, anterior communicating artery; CMA, middle cerebral artery; IA, intracranial aneurysm; ICA, internal carotid artery; L, left; $R$, right. 
surgical exposition. This procedure demands an experienced surgeon with a very low incidence of complications. The high-risk nature of this procedure, as well as the decline in the number of these surgeries performed annually due to the advent of the endovascular technique, created a gap in the training of young neurosurgeons and vascular surgeons. Additive manufactured models for the simulation of $\mathrm{CE}$ have demonstrated that they provide comprehensive training and allow the residents to obtain skills before operating on a patient. ${ }^{47}$

In the same way, biomodels were also validated for preoperative planning in the endovascular treatment of vascular diseases with microcatheter molding ${ }^{48,49}$ and in the endovascular treatment of intracranial arterial stenosis. ${ }^{50}$

Three-dimensional models were used in brain tumors to evaluate the association between healthy and adjacent neoplastic tissues and to help delineating the resection borders. Three-dimensional printing of brain tumors uses the fusion of CT and MRI images as its basis, improving anatomical comprehension.

Currently, neuro-oncological preoperative planning is based on imaging exams, mainly on MRI, since it provides more detailed images of the brain tissues. The use of perfusion techniques and tractography can also provide important details for the choice of the approach to be used by the neurosurgeon. In the same way, stereotaxis and neuronavigation came to facilitate pre- and intraoperative planning, since they provide the location of intracranial structures, in real time, on the previously acquired imaging exams. ${ }^{51}$ However, even if these images supply important details for the preoperative planning, some difficulties still persist in the differentiation between tumor lesions and the underlying cerebral structures. Additive manufacturing technology allowed the MRI data to be transduced into tailor-made biomodels describing the relationship between tumor, vasculature, and cerebral tissue, facilitating the understanding and, consequently, resulting in the planning of the most effective treatment. ${ }^{52}$

The validity of this technique was confirmed by reports of preoperative planning using tractography in 3D models, mainly when used in complex tumor resection surgeries, such those of gliomas. Diffuse low-grade gliomas are infiltrative tumors that pervade cortical and subcortical structures in the brain. The understanding of the anatomical relationships, case by case, is fundamental for a successful neurosurgical therapy. Additive manufacturing based on tractography images can improve the skills of the surgeon to plan and to treat these types of lesions. This process can reduce surgical time and contributes to increased safety to the patient in tumor resection surgeries when nerve tracts are involved or are part of the tumor approach. $^{53}$

Skull base tumors surgeries also benefit from the use of AM due to the extreme difficulty of the surgical approach and to the anatomical complexity. ${ }^{54,55}$ In these lesions, deeper areas are not visible in prototyped models manufactured with opaque materials. Additive manufacturing techniques were refined through the years and, now, translucent materials can be printed providing a better visualization of the structures involved with the lesion. ${ }^{56}$

The use of 3D printing has brought the development of simulators created from the construction of the skull, with all its components, using a variety of materials with consistency and density very close to reality. Polyjet technology has become the preferred method to print devices for this purpose. $^{57}$

One of the simplest indications of the AM technology was in the development of molds for the reconstruction of cranial bone defects. In neurosurgery, the need for large craniectomies for cerebral decompression in cases of traumas or extensive ischemic strokes when the edema can cause expressive increase of the intracranial pressure is well-known. As a routine, after the acute phase, the closure of the bone defect (cranioplasty) is performed with metilmetacrilate, which is manipulated by the surgeon intraoperatively. ${ }^{58-61}$ However, the cranioplasty of large bone defects does not always result in suitable esthetic outcomes. Therefore, 3D tailor-made molds for cranioplasty are very useful.

Recently, 3D printing has also been used in pediatric neurosurgery, as in the case of surgical correction of the meningoencephalocele. These are rare diseases, and few pediatric neurosurgeons are comfortable with performing this kind of surgery. In this context, the use of biomodels is fundamental to establish reliable and safe surgical techniques for each case. The anatomical relationship between the brain and the skull can be represented by biomodels, clearly demonstrating the involved lesions. Additive manufacturing technology allows the previous planning of the surgical approach and the development of strategies to deal with several intraoperative high-risk. Three-dimensional printed models offer not only a better view of the planning process, but also provide substantial information to enhance the precision of surgical reconstruction in meningoencephalocele surgeries. $^{62}$

In pediatric neurosurgery, a short anesthetic time, as well as reduced radiological exposure and blood loss, are very important. It was observed that, with the use of 3D models, the duration of surgery was reduced when compared with procedures that did not use this technology. ${ }^{63}$

Like surgical correction of meningoencephalocele, surgeries for skull reconstruction due to craniosynostosis also benefit from manufactured models (-Fig. 7). Frequently, craniosynostosis is a complex disease, usually involving orbital and facial bones along with cranial deformity. Sometimes, surgical treatment is challenging, and it almost always requires a multidisciplinary approach, with association of a neurosurgeon and a plastic surgeon. The complexity of this surgery lies in the multiple possibilities of reconstructions, which would benefit from pre- and intraoperative definitions of biometrics and esthetics. Threedimensional printing transforms the virtual planning into anatomical replicas of the cranium, which can be manipulated and fitted, as a jigsaw puzzle, to find the best reconstruction form. ${ }^{64,65}$ 


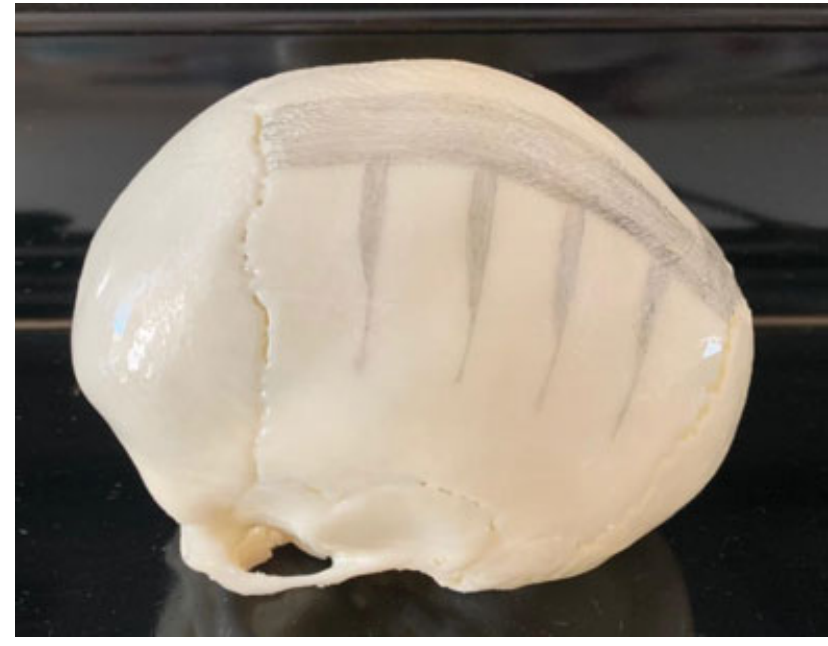

Fig. 7 Craniostenosis model.

Surgeries for resection and cranial reconstruction due to fibrous dysplasia, a benign pathological development of the bone, can also have their planning aided by 3D models. ${ }^{66}$

Another common neurosurgical procedure of interest for the development of simulation using AM is endoscopic thirdventriculostomy (ETV).

Endoscopic third-ventriculostomy and intraventricular biopsy surgeries are procedures whose training is particularly complicated due to the relatively small number of cases and to the involved techniques that are different from those used in conventional neurosurgery. Three-dimensional printed models can simulate the scenario for neuroendoscopic procedures, allowing safe and effective teaching in a realistic and repetitive way. ${ }^{67}$ An important advance in some of these simulation devices is the addition of a ventricular system full of liquid that can provide variable ventricular pressures. $^{68}$

Endoscopic transnasal surgeries have also been another important and pioneering area in the integration of $3 \mathrm{D}$ printing in the development of surgical simulation. A physical simulation can reproduce the complex anatomy of the anterior fossa and provide useful ways to apprehend the necessary abilities in a safe and effective scenario. ${ }^{69,70}$

Using implantable electrodes, the surgeon evaluates the epileptogenic cortical area and can also have the location of the implant defined through 3D models. ${ }^{71}$

In the literature, a growing number of papers describe the use of $3 \mathrm{D}$ printing for spine surgeries in the last years. A recent systematic review on the applications of AM in spine surgery found $>2,400$ articles on the subject. It concluded that 3D printing is rapidly becoming intimately integrated with surgical interventions in the spine. Currently, it is used for surgical planning and intraoperative guidance, besides aiding the production of tailor-made prostheses. The technology allows the reduction of the surgical time and better surgical results (- Fig. 8). ${ }^{72-74}$

Clinical benefits such as improved diagnosis, reduction of the time of fluoroscopy, reduction of the surgical time, decrease of intraoperative bleeding, better communication

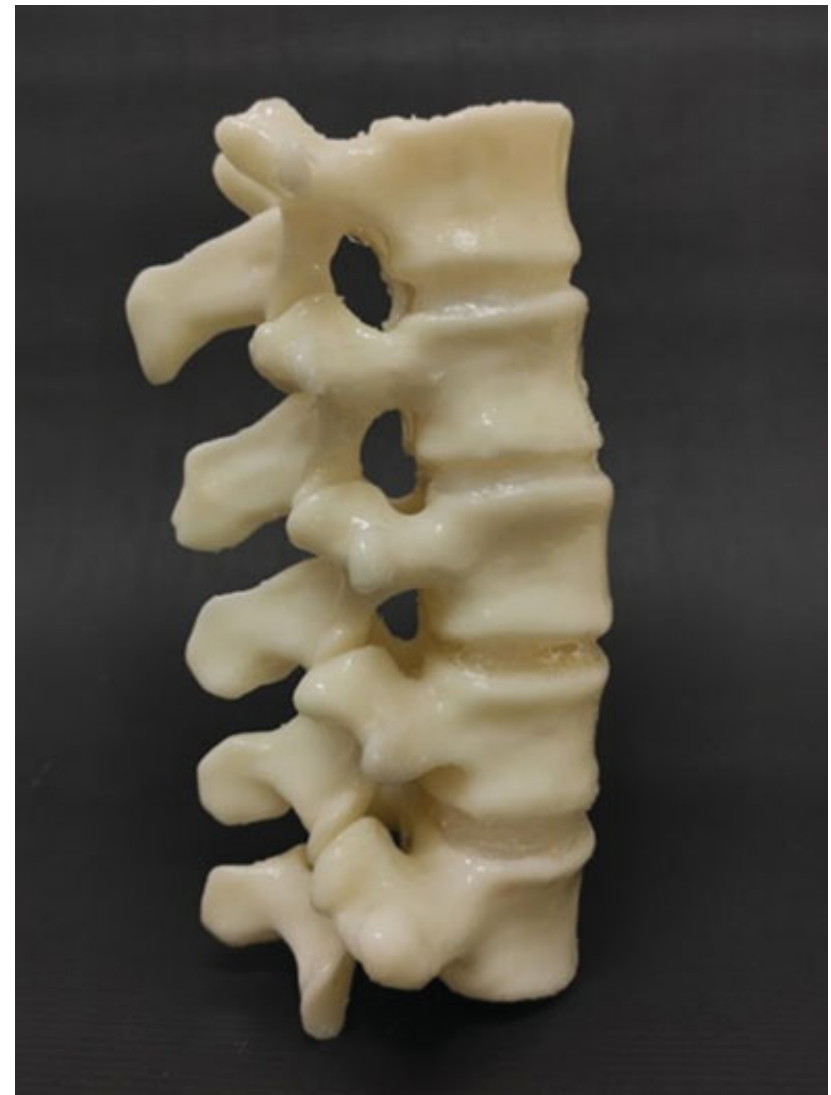

Fig. 8 Spine model.

of the surgical team, and a lower index of malpositioning of screws were reported. $8,74,75$

Pedicular screws are routine for spine neurosurgeons, since they are the most effective way to stabilize the vertebrae. ${ }^{76}$ However, the traditional implantation techniques are associated with many problems and present a high risk of violation of the pedicle, with the possibility of causing potentially fatal neurovascular damages. ${ }^{77}$

Three-dimensional guidance can offer an alternative, simple, convenient, and low-cost way to improve the precision of the positioning of pedicular screws.

Currently, one of the most important applications of 3D printing in spine surgery is the capacity to manufacture the tailor-made implants for the patient. First, an imaging exam is performed and a specific prosthesis for the patient can be prototyped. Despite its innovation, this process is still very expensive. $^{78,79}$

Three-dimensional printing with a material based on plaster was used to create $n$ touchable anatomical model of the lumbosacral spine according to the CT image. These models can be used to perform a variety of procedures, including interventions in pain management, such as epidural and nerve roots blockades, facets injections, and blood patching in cases of cerebrospinal fluid (CSF) hypotension. ${ }^{80}$

Craniovertebral joint anomalies can be very difficult to be treated surgically. The preoperative information on bone anomalies, the pathway of the vertebral arteries, the size of bone pedicles, and the location of the transverse foramens 
are important for the surgeons. The sizes of the plates and screws to be used, as well as the angle of screw insertion, can be calculated based on the data of the models. ${ }^{81,82}$

Also, this technique can be applied in the treatment of atlantoaxial basilar invagination and displacement. Threedimensional printing can give detailed information about the abnormalities of the bone structure and of the vertebral artery pathway. It is useful to configure the surgery strategy and to project the access point and the pathway of the screw, consequently avoiding lesions of the vertebral artery and of the bone marrow. ${ }^{83}$

Neuromodulation techniques can provide an analgesic treatment for patients with chronic pain. Sometimes, these treatment techniques can fail due to a mistake in the access to the peridural space. Three-dimensional printing can provide additional information to improve the odds of access when the anatomy is distorted. ${ }^{84}$

\section{D Printing in Neurological Clinical Practice}

While 3D printing is intuitively attractive, several barriers exist for its widespread implementation. The process of construction of the model can be partially automated, but for clinical use, some care should be taken during this process. The final quality of the biomodels depends on the quality of the acquired image from cerebral imaging exams. A careful analysis is required when segmentation is made manually, due to the complexity, the reduced sizes, and irregular pathways of the brain structures. The specialized manipulation of the segmentation programs by AM, imaging, 3D files generation technicians in is of extreme importance. Technical knowledge of operating systems and segmentation software is of crucial importance.

The final quality of the biomodel depends on the several stages of its production, from the acquisition of images through CT and MRI to the actual final printing. The quality of the equipment used also influences the final result of the pieces. The largest discrepancies of the production of biomodels correspond to their dimensions, which are related to the thickness of each printed slice. Taft et al. ${ }^{85}$ described that the absolute magnitude of error was small and within the tolerance range generally accepted for the treatment of a patient. Therefore, the stages of quality control or the validation of the model are crucial when the printed models in $3 \mathrm{D}$ are used for the sizing of the device. A survey of evaluations of the models should always be considered, for instance, by means of the evaluation of the images of the biomodels with the same imaging techniques from which they were originated. In the case of IA biomodels, the evaluation can be processed by comparing the measurements of the neck, of the height of the aneurysm, and of the diameter of the involved cerebral arteries. ${ }^{43}$

Also, another important factor is the high cost of 3D printers, in addition to the fact that almost all of them still depend on technicians for handling. The materials used to build the object also involve high prices and are difficult to be obtained.

One of the main limitations of AM is that the current technologies cannot print directly ultramalleable materials, such as human cerebral tissues. A new method was proposed to create a 3D model - both anatomical and tactile - of the human brain based on MRI and CT images. The production process consists of three stages and uses the solid 3D model of the brain, followed by the construction of a negative silicon mold of the first model and using it as a model for the creation of a piece produced with a jelly that resembles the original consistence of the human brain. ${ }^{86,87}$

The production of tailor-made biomodels, which initiates with the acquisition of the images and ends with the impression of the piece, is time-consuming. The time required to produce a model varies, on average, from a few to 12 hours, depending on the size of the printed object, and can take up to 24 hours if the desired object is a complete skull. In this context, the use of biomodels is only possible in elective cases, and their use in emergencies remains very restricted. ${ }^{16,17}$

Only one paper described the use of emergency 3D printing in neurosurgery. The authors developed a method to produce solid models of cerebral aneurysms, with a shorter time of impression than those of the conventional methods, using a compact 3D printer with acrylonitrilebutadiene-styrene (ABS) resin. ${ }^{88}$

Three-dimensional printers are developing quickly; consequently, due to their popularity, their cost is decreasing. The generation of $3 \mathrm{D}$ files, such as the files with 'STL' extension derived from Digital Imaging and Communications in Medicine (DICOM) data, is being recognized as a clinical need, and this ability is being introduced in the software of several imaging diagnosis medical equipment. Currently, CT and MRI equipment that automatically generate '.STL' files already exist, enabling the presentation of the results of the exams both in $2 \mathrm{D}$ and in $3 \mathrm{D}$ printing.

Tailor-made production of biomaterials is already a fact. However, the envisioned future is the printing of human tissues. Bioprinting has achieved thin layers of tissues that are biologically active and can be used for pharmaceutical tests. A promising development area is 3D bioprinting of neurovascular units and the contribution of the different types of cells for the neurovascular function. Also, dysfunctions can be studied at the molecular and cellular levels. ${ }^{20,89-92}$

\section{Conclusions}

Additive manufacturing in neurosurgery with educational and clinical purposes is highly promising and will probably widen its use and application. Although challenges still exist due to the cost of production of 3D printing, as well as to the limitations in the available materials, these current barriers shall be overcome with new research and technological progress.

Until now, 3D printing has focused on the increase and demonstration of the applicability of this technology, showing its usefulness in preoperative planning and training, as well as in the acquisition of neurosurgical skills, besides in the improvement of the education of physicians and patients.

To establish the use of AM in the neurosurgical practice, further studies focusing on demonstrable clinical results 
and on suiting them to the use of this technique will be needed. For instance, the choice of surgical materials in preoperative planning can avoid unnecessary expenses and reduce manipulation of the cerebral structures. Given the path of the $3 \mathrm{D}$ printing technology and its usefulness already demonstrated in multiple clinical scenarios, its widespread application in neurosurgery, in the future, seems to be inevitable.

Additive manufacturing provides an exclusive way for direct replication of the specific pathologies of the patient. It can identify the anatomical variation and provide a way for rapid construction of training models, allowing the medical resident and the experienced neurosurgeon to practice the surgical steps before the operation.

As a future perspective, it is necessary to move beyond the current state of 3D biomodels that represent actual 3D anatomical reconstructions. These models still do not provide simulations of more delicate maneuvers, which involve real blood consequences. The use of materials with a consistency similar those of the cerebral and spinal tissues, as well as the simulation of bleeding, should be developed. Therefore, the next steps must overcome these challenges.

\section{Contributions of the Authors}

Leal A. G.: Conception and design, data analysis and interpretation, drafting of the manuscript; Ramina R.: Critical revision of the manuscript, reading and approval of the final manuscript; Aguiar P. H. P.: critical revision of the manuscript, reading and approval of the final manuscript; Souza M. A.: Research supervision and critical revision of the manuscript, reading and approval of the final manuscript; Fernandes B. L.: critical revision of the manuscript, reading and approval of the final manuscript; Nohama P.: research supervision and critical revision of the manuscript, reading and approval of the final manuscript.

\section{Conflict of Interests}

The authors have no conflict of interests to declare.

\section{References}

1 McGurk M, Amis AA, Potamianos P, Goodger NM. Rapid prototyping techniques for anatomical modelling in medicine. Ann $\mathrm{R}$ Coll Surg Engl 1997;79(03):169-174

2 Lo LJ, Chen YR. Three-dimensional computed tomography imaging in craniofacial surgery: morphological study and clinical applications. Chang Gung Med J 2003;26(01):1-11

3 Nishimura PLG, Rodrigues OV, Botura G Jr, Silva LA. Prototipagem rápida: um comparativo entre uma tecnologia aditiva e uma subtrativa. In: Anais do $12^{\circ}$ Congresso Brasileiro de Pesquisa e Desenvolvimento em Design. São Paulo: Blucher, 2016. Blucher Design Proceedings 2016;9(02):4481-91

4 Esses SJ, Berman P, Bloom AI, Sosna J. Clinical applications of physical 3D models derived from MDCT data and created by rapid prototyping. AJR Am J Roentgenol 2011;196(06):W683-8

5 Vloeberghs M, Glover A, Benford S, Jones A, Wang P, Becker A. Virtual neurosurgery, training for the future. Br J Neurosurg 2007; 21(03):262-267
6 Louvrier A, Marty P, Barrabé A, et al. How useful is 3D printing in maxillofacial surgery? J Stomatol Oral Maxillofac Surg 2017;118 (04):206-212

7 Velasco I, Vahdani S, Ramos H. Low-cost Method for Obtaining Medical Rapid Prototyping Using Desktop 3D printing: A Novel Technique for Mandibular Reconstruction Planning. J Clin Exp Dent 2017;9(09):e1103-e1108

8 D'Urso PS, Barker TM, Earwaker WJ, et al. Stereolithographic biomodelling in cranio-maxillofacial surgery: a prospective trial. J Craniomaxillofac Surg 1999;27(01):30-37

9 Lin HH, Lonic D, Lo LJ. 3D printing in orthognathic surgery - A literature review. J Formos Med Assoc 2018;117(07):547-558

10 Chan HH, Siewerdsen JH, Vescan A, Daly MJ, Prisman E, Irish JC. 3D Rapid Prototyping for Otolaryngology-Head and Neck Surgery: Applications in Image-Guidance, Surgical Simulation and PatientSpecific Modeling. PLoS One 2015;10(09):e0136370

11 Eltorai AE, Nguyen E, Daniels AH. Three-Dimensional Printing in Orthopedic Surgery. Orthopedics 2015;38(11):684-687

12 Sheth R, Balesh ER, Zhang YS, Hirsch JA, Khademhosseini A, Oklu R. Three-Dimensional Printing: An Enabling Technology for IR. J Vasc Interv Radiol 2016;27(06):859-865

13 Dankowski R, Baszko A, Sutherland M, et al. 3D heart model printing for preparation of percutaneous structural interventions: description of the technology and case report. Kardiol Pol 2014;72(06):546-551

14 Sardari Nia P, Heuts S, Daemen J, et al. Preoperative planning with three-dimensional reconstruction of patient's anatomy, rapid prototyping and simulation for endoscopic mitral valve repair. Interact Cardiovasc Thorac Surg 2017;24(02):163-168

15 Volpato NPrototipagem Rápida. Tecnologias e Aplicações. São Paulo: Blucher; 2007. 272 p.

16 Erbano BO, Opolski AC, Olandoski M, et al. Rapid prototyping of three-dimensional biomodels as an adjuvant in the surgical planning for intracranial aneurysms. Acta Cir Bras 2013;28(11): 756-761

17 Leal AG, Pagnan LB, Kondo RT, Foggiatto JA, Agnoletto GJ, Ramina R. Elastomers three-dimensional biomodels proven to be a trustworthy representation of the angiotomographic images. Arq Neuropsiquiatr 2016;74(09):713-717

18 Gorni AA. Introdução à prototipagem rápida e seus processos. [cited 2013 Sep 15]. Available from: http://www.gorni.eng.br/protrap.html

19 Grimm T. User's guide to rapid prototyping. Dearborn, MI: Society of Manufacturing Engineeers; 2004. 404 p.

20 Tappa K, Jammalamadaka U. Novel Biomaterials Used in Medical 3D Printing Techniques. J Funct Biomater 2018;9(01):E17

21 International Standard. ISO/ASTM 52900:2015(E): Additive manufacturing - General principles - Terminology 2015. Available at: https://www.colliercountyfl.gov/home/showdocument? id $=90543$

22 Berry E, Brown JM, Connell M, et al. Preliminary experience with medical applications of rapid prototyping by selective laser sintering. Med Eng Phys 1997;19(01):90-96

23 Park J, Tari MJ, Hahn HT. Characterization of the laminated object manufacturing (LOM) process. Rapid Prototyping Journal 2000;6 (01):36-50

24 D'Urso PS, Thompson RG, Atkinson RL, et al. Cerebrovascular biomodelling: a technical note. Surg Neurol 1999;52(05): 490-500

25 Iacoangeli M, Nocchi N, Nasi D, et al. Minimally Invasive Supraorbital Key-hole Approach for the Treatment of Anterior Cranial Fossa Meningiomas. Neurol Med Chir (Tokyo) 2016;56(04): 180-185

26 Garrido BJ, Wood KE. Navigated placement of iliac bolts: description of a new technique. Spine J 2011;11(04):331-335

27 Balachandran R, Fitzpatrick JM, Labadie RF. Accuracy of imageguided surgical systems at the lateral skull base as clinically 
assessed using bone-anchored hearing aid posts as surgical targets. Otol Neurotol 2008;29(08):1050-1055

28 Randazzo M, Pisapia JM, Singh N, Thawani JP. 3D printing in neurosurgery: A systematic review. Surg Neurol Int 2016;7 (Suppl 33):S801-S809

29 Hopper KD, Pierantozzi D, Potok PS, et al. The quality of 3D reconstructions from 1.0 and 1.5 pitch helical and conventional CT. J Comput Assist Tomogr 1996;20(05):841-847

30 Barker TM, Earwaker WJ, Lisle DA. Accuracy of stereolithographic models of human anatomy. Australas Radiol 1994;38(02): 106-111

31 Hespel AM. Three-Dimensional Printing Role in Neurologic Disease. Vet Clin North Am Small Anim Pract 2018;48(01):221-229

32 Abla AA, Lawton MT. Three-dimensional hollow intracranial aneurysm models and their potential role for teaching, simulation, and training. World Neurosurg 2015;83(01):35-36

33 Wurm G, Tomancok B, Pogady P, Holl K, Trenkler J. Cerebrovascular stereolithographic biomodeling for aneurysm surgery. Technical note. J Neurosurg 2004;100(01):139-145

34 Ishikawa T, Morita A, Fukushima T, Ono H. Three-Dimensional Cerebral Aneurysm Models for Surgical Simulation and Education - Development of Aneurysm Models with Perforating Arteries and for Application of Fenestrated Clips. Open Journal of Modern Neurosurgery 2014;4(02):59-63

35 Anderson JR, Thompson WL, Alkattan AK, et al. Three-dimensional printing of anatomically accurate, patient specific intracranial aneurysm models. J Neurointerv Surg 2016;8(05):517-520

36 Ionita CN, Mokin M, Varble N, et al. Challenges and limitations of patient-specific vascular phantom fabrication using 3D Polyjet printing. Proc SPIE Int Soc Opt Eng 2014; 9038:90380M.

37 Kondo K, Nemoto M, Masuda H, et al. Anatomical Reproducibility of a Head Model Molded by a Three-dimensional Printer. Neurol Med Chir (Tokyo) 2015;55(07):592-598

38 Lawton MT, Spetzler RF. Surgical management of giant intracranial aneurysms: experience with 171 patients. Clin Neurosurg 1995;42:245-266

39 Rinne J, Hernesniemi J, Niskanen M, Vapalahti M. Management outcome for multiple intracranial aneurysms. Neurosurgery 1995;36(01):31-37, discussion 37-38

40 Kimura T, Morita A, Nishimura K, et al. Simulation of and training for cerebral aneurysm clipping with 3-dimensional models. Neurosurgery 2009;65(04):719-725, discussion 725-726

41 Mashiko T, Otani K, Kawano R, et al. Development of threedimensional hollow elastic model for cerebral aneurysm clipping simulation enabling rapid and low cost prototyping. World Neurosurg 2015;83(03):351-361

42 Mashiko T, Kaneko N, Konno T, Otani K, Nagayama R, Watanabe E. Training in cerebral aneurysm clipping using self-made 3-Dimensional models. J Surg Educ 2017;74(04):681-689

43 Leal A, Souza M, Nohama P. Additive Manufacturing of 3D Biomodels as Adjuvant in Intracranial Aneurysm Clipping. Artif Organs 2019;43(01):E9-E15

44 Weinstock P, Prabhu SP, Flynn K, Orbach DB, Smith E. Optimizing cerebrovascular surgical and endovascular procedures in children via personalized 3D printing. J Neurosurg Pediatr 2015;16(05): 584-589

45 Dong M, Chen G, Qin K, et al. Development of three-dimensional brain arteriovenous malformation model for patient communication and young neurosurgeon education. Br J Neurosurg 2018; 32(06):646-649

46 Shah A, Jankharia B, Goel A. Three-dimensional model printing for surgery on arteriovenous malformations. Neurol India 2017;65 (06):1350-1354

47 Santangelo G, Mix D, Ghazi A, Stoner M, Vates GE, Stone JJ. Development of a Whole-Task Simulator for Carotid Endarterectomy. Oper Neurosurg (Hagerstown) 2018;14(06):697-704. Doi: 10.1093/ons/opx209
48 Ishibashi T, Takao H, Suzuki T, et al. Tailor-made shaping of microcatheters using three-dimensional printed vessel models for endovascular coil embolization. Comput Biol Med 2016; 77:59-63

49 Namba K, Higaki A, Kaneko N, Mashiko T, Nemoto S, Watanabe E. Microcatheter shaping for intracranial aneurysm coiling using the 3-dimensional printing rapid prototyping technology: preliminary result in the first 10 consecutive cases. World Neurosurg 2015;84(01):178-186

$50 \mathrm{Xu} \mathrm{WH}$, Liu J, Li ML, Sun ZY, Chen J, Wu JH. 3D printing of intracranial artery stenosis based on the source images of magnetic resonance angiograph. Ann Transl Med 2014;2(08):74

51 Silva Jr EBda, Aurich LA, Silva LFMda Jr., Milano JB, Ramina M. Neuronavigation for Intracranial Meningiomas. J Bras Neurocirurg 2011;22(04):143-149

52 Oishi $\mathrm{M}$, Fukuda $\mathrm{M}$, Yajima $\mathrm{N}$, et al. Interactive presurgical simulation applying advanced 3D imaging and modeling techniques for skull base and deep tumors. J Neurosurg 2013;119(01): 94-105

53 Gargiulo P, Árnadóttir Î, Gíslason M, Edmunds K, Ólafsson I. New Directions in 3D Medical Modeling: 3D-Printing Anatomy and Functions in Neurosurgical Planning. J Healthc Eng 2017; 2017:1439643

54 Wanibuchi M, Noshiro S, Sugino T, et al. Training for Skull Base Surgery with a Colored Temporal Bone Model Created by ThreeDimensional Printing Technology. World Neurosurg 2016; 91:66-72

55 Muelleman TJ, Peterson J, Chowdhury NI, Gorup J, Camarata P, Lin J. Individualized Surgical Approach Planning for Petroclival Tumors Using a 3D Printer. J Neurol Surg B Skull Base 2016;77 (03):243-248

56 Kondo K, Harada N, Masuda H, et al. A neurosurgical simulation of skull base tumors using a 3D printed rapid prototyping model containing mesh structures. Acta Neurochir (Wien) 2016;158 (06):1213-1219

57 Waran V, Narayanan V, Karuppiah R, Owen SL, Aziz T. Utility of multimaterial 3D printers in creating models with pathological entities to enhance the training experience of neurosurgeons. J Neurosurg 2014;120(02):489-492

58 Lara WC, Schweitzer J, Lewis RP, Odum BC, Edlich RF, Gampper TJ. Technical considerations in the use of polymethylmethacrylate in cranioplasty. J Long Term Eff Med Implants 1998;8(01): 43-53

59 Cheng AC, Wee AG. Reconstruction of cranial bone defects using alloplastic implants produced from a stereolithographically-generated cranial model. Ann Acad Med Singap 1999;28(05): 692-696

60 Wulf J, Busch LC, Golz T, et al. CAD generated mold for preoperative implant fabrication in cranioplasty. Stud Health Technol Inform 2005;111:608-610

61 Tan ET, Ling JM, Dinesh SK. The feasibility of producing patientspecific acrylic cranioplasty implants with a low-cost 3D printer. J Neurosurg 2016;124(05):1531-1537

62 Coelho G, Chaves TMF, Goes AF, Del Massa EC, Moraes O, Yoshida M. Multimaterial 3D printing preoperative planning for frontoethmoidal meningoencephalocele surgery. Childs Nerv Syst 2018;34(04):749-756

63 Martelli N, Serrano C, van den Brink H, et al. Advantages and disadvantages of 3-dimensional printing in surgery: A systematic review. Surgery 2016;159(06):1485-1500

64 LoPresti M, Daniels B, Buchanan EP, Monson L, Lam S. Virtual surgical planning and 3D printing in repeat calvarial vault reconstruction for craniosynostosis: technical note. J Neurosurg Pediatr 2017;19(04):490-494

65 Ghizoni E, de Souza JPSAS, Raposo-Amaral CE, et al. 3D-Printed Craniosynostosis Model: New Simulation Surgical Tool. World Neurosurg 2018;109:356-361 
66 Nahumi N, Shohet MR, Bederson JB, Elahi E. Frontorbital Fibrous Dysplasia Resection and Reconstruction With Custom Polyetherlatone Alloplast. J Craniofac Surg 2015;26(08):e720-e722

67 Waran V, Narayanan V, Karuppiah R, et al. Neurosurgical endoscopic training via a realistic 3-dimensional model with pathology. Simul Healthc 2015;10(01):43-48

68 Ryan JR, Chen T, Nakaji P, Frakes DH, Gonzalez LF. Ventriculostomy Simulation Using Patient-Specific Ventricular Anatomy, 3D Printing, and Hydrogel Casting. World Neurosurg 2015;84(05): 1333-1339

69 Narayanan V, Narayanan P, Rajagopalan R, et al. Endoscopic skull base training using 3D printed models with pre-existing pathology. Eur Arch Otorhinolaryngol 2015;272(03):753-757

70 Waran V, Menon R, Pancharatnam D, et al. The creation and verification of cranial models using three-dimensional rapid prototyping technology in field of transnasal sphenoid endoscopy. Am J Rhinol Allergy 2012;26(05):132-136

71 Naftulin JS, Kimchi EY, Cash SS. Streamlined, Inexpensive 3D Printing of the Brain and Skull. PLoS One 2015;10(08):e0136198

72 Wilcox B, Mobbs RJ, Wu AM, Phan K. Systematic review of 3D printing in spinal surgery: the current state of play. J Spine Surg 2017;3(03):433-443

73 D'Urso PS, Askin G, Earwaker JS, Merry GS, Thompson RG, Barker TM, et al. Spinal biomodeling. Spine 1999;24(12):1247-1251

74 Izatt MT, Thorpe PL, Thompson RG, et al. The use of physical biomodelling in complex spinal surgery. Eur Spine J 2007;16(09): 1507-1518

75 Wu ZX, Huang LY, Sang HX, et al. Accuracy and safety assessment of pedicle screw placement using the rapid prototyping technique in severe congenital scoliosis. J Spinal Disord Tech 2011;24(07): 444-450

76 Provaggi E, Leong JJH, Kalaskar DM. Applications of 3D printing in the management of severe spinal conditions. Proc Inst Mech Eng H 2017;231(06):471-486

77 Lu S, Xu YQ Zhang YZ, et al. A novel computer-assisted drill guide template for lumbar pedicle screw placement: a cadaveric and clinical study. Int J Med Robot 2009;5(02):184-191

78 Phan K, Sgro A, Maharaj MM, D'Urso P, Mobbs RJ. Application of a 3D custom printed patient specific spinal implant for $\mathrm{C} 1 / 2$ arthrodesis. J Spine Surg 2016;2(04):314-318

79 Mobbs RJ, Coughlan M, Thompson R, Sutterlin CE III, Phan K. The utility of 3D printing for surgical planning and patient-specific implant design for complex spinal pathologies: case report. J Neurosurg Spine 2017;26(04):513-518
80 Javan R, Bansal M, Tangestanipoor A. A Prototype Hybrid GypsumBased 3-Dimensional Printed Training Model for Computed Tomography-Guided Spinal Pain Management. J Comput Assist Tomogr 2016;40(04):626-631

81 Goel A, Jankharia B, Shah A, Sathe P. Three-dimensional models: an emerging investigational revolution for craniovertebral junction surgery. J Neurosurg Spine 2016;25(06):740-744

82 Gao F, Wang Q, Liu C, Xiong B, Luo T. Individualized 3D printed model-assisted posterior screw fixation for the treatment of craniovertebral junction abnormality: a retrospective study. J Neurosurg Spine 2017;27(01):29-34

83 Yin Y, Yu X, Tong H, Xu T, Wang P, Qiao G. [Exploratory study of 3D printing technique in the treatment of basilar invagination and atlantoaxial dislocation]. Zhonghua Yi Xue Za Zhi 2015;95(37): 3004-3007

84 Taverner MG, Monagle JP. Three-Dimensional Printing: An Aid to Epidural Access for Neuromodulation. Neuromodulation 2017;20 (06):622-626

85 Taft RM, Kondor S, Grant GT. Accuracy of rapid prototype models for head and neck reconstruction. J Prosthet Dent 2011;106(06): 399-408

86 Ploch CC, Mansi CSSA, Jayamohan J, Kuhl E. Using 3D Printing to Create Personalized Brain Models for Neurosurgical Training and Preoperative Planning. World Neurosurg 2016;90:668-674

87 Mashiko T, Konno T, Kaneko N, Watanabe E. Training in Brain Retraction Using a Self-Made Three-Dimensional Model. World Neurosurg 2015;84(02):585-590

88 Konno T, Mashiko T, Oguma H, Kaneko N, Otani K, Watanabe E. [Rapid 3-Dimensional Models of Cerebral Aneurysm for Emergency Surgical Clipping]. No Shinkei Geka 2016;44(08): $651-660$

89 Ma X, Qu X, Zhu W, et al. Deterministically patterned biomimetic human iPSC-derived hepatic model via rapid 3D bioprinting. Proc Natl Acad Sci U S A 2016;113(08):2206-2211

90 Potjewyd G, Moxon S, Wang T, Domingos M, Hooper NM. Tissue Engineering 3D Neurovascular Units: A Biomaterials and Bioprinting Perspective. Trends Biotechnol 2018;36(04): 457-472

91 Zhu W, Cui H, Boualam B, et al. 3D bioprinting mesenchymal stem cell-laden construct with core-shell nanospheres for cartilage tissue engineering. Nanotechnology 2018;29(18):185101

92 Daly AC, Pitacco P, Nulty J, Cunniffe GM, Kelly DJ. 3D printed microchannel networks to direct vascularisation during endochondral bone repair. Biomaterials 2018;162:34-46 